\title{
A PROPOSED METHODOLOGY TO EVALUATE SPECIFIC APPLICATIONS OF EXTENDED SURFACES IN INDUSTRIAL EQUIPMENT
}

\author{
A. L. G. Ferreira, \\ C. S. Stampa, \\ D. C. Lobão, \\ ABSTRACT \\ The concept of Passive Cooling fits into a number of technological options \\ involving constructive elements, whereby the heat exchange area of a \\ surface being cooled by a surrounding fluid medium occurs. Thus, the \\ and G. B. Alvarez \\ increase in area results in an increase in the surface heat dissipation rate for \\ the refrigerant, inferring only a single cost, i.e. the construction cost. Among \\ the available technical possibilities, the use of extended surfaces, known as \\ Universidade Federal Fluminense \\ fins, stands out. The present work focuses on the use of fins on three very \\ common electrical devices in the industrial environment, which present a \\ great need for cooling.They are: three-phase transformer, frequency inverter \\ and induction electric motor. The study is dedicated to a theoretical \\ evaluation of the use of the fin profiles used in these equipments, since the \\ manufacturers do not make their design data available to the public. Thus, a \\ methodology was developed for this evaluation, including comparison of \\ the results between the original profiles of these equipments with an \\ alternative profile of similar design. Within the process of calculating the \\ heat dissipation rates by the fins, the axial temperature distribution profiles \\ were numerically determined using the Finite Difference discretization \\ method, together with the Gauss-Seidel iterative method for the resolution \\ of the discretized equations. The computational code was developed using \\ MatLab $^{\circledR}$ software. The results of the present work attested to the proper use \\ of the original profiles employed by the manufacturers. \\ Received: February 17, 2020 \\ Revised: March 03, 2020 \\ Accepted: May 28, 2020 \\ Keywords: extended surfaces, electrical devices, thermal performance.
}

\section{NOMENCLATURE}

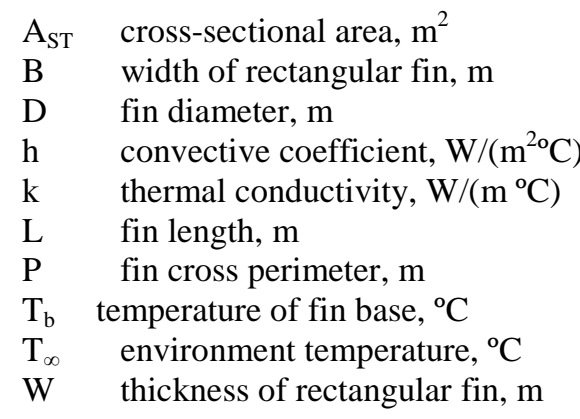

\section{Subscripts}

$$
\begin{array}{ll}
\text { Opt } & \text { optimal } \\
\mathrm{N} & \text { numeric values } \\
\mathrm{E} & \text { exact values }
\end{array}
$$

\section{INTRODUCTION}

The use of extended surfaces, known as fins, has been proving over several decades to be the most effective and inexpensive way to increase the heat transfer rate between a hot solid surface and a cold fluid around it (Azizand Kraus,1995;Aziz and Fang, 2010).

In the early 1960s, with the development of the space age, fins with radial surfaces became common in the design of space cooling systems in spacecraft and gained popularity in the last thirty years, when they were applied to the cooling of electronic devices, leading to a substantial increase in heat dissipation rates(Aziz and Fang, 2010).

According to Ganorkar and Kriplani (2011), Nagarani et al. (2014) and Marchetta et al. (2008), the advancement of technology and the need to improve heat transfer coefficients, led engineering to design different fin geometries in order to search profiles most suitable for each application. Aziz (1992) describes that fin optimization can be divided into two groups. In the first, for a known fin geometry and volume, it is necessary to determine which dimensions would lead to the maximum heat dissipation rate. The second group, on the other hand, deals with the determination of the fin geometry or profile, such that the fin volume is minimal in order to meet a specific rate of heat dissipation.

Mokheimer (2003) analyzed the effect of the temperature-dependent convective coefficient on the 
efficiency of fins with different profiles, in contrast of the hypothesis of constant coefficients. The results showed that constant coefficients lead to a significant underestimation of the fin efficiency. In similar studies, Nnanna et al (2003) presented a generalized analytical solution of the Energy equation. In this work, they investigated the influence on the fin heat dissipation rate concerning with the curvature, geometry and convective coefficient of heat transfer, taking into account the laminar and turbulent flow regimes for the ambient fluid. The results with respect to the use between temperature-dependent convective coefficients and constant convective coefficients showed a significant difference for small values of the geometric parameter, $\left(\mathrm{m}_{0} \mathrm{~L}\right) \varepsilon^{1 / 2}$, while this difference was considered negligible for large values of this parameter.

Eu Ong et al. (2005) worked on the development of ideal surfaces for rectangular and cylindrical fin profiles, optimizing heat dissipation rates. Unlike Mokheimer (2003), they used the technique of genetic algorithms (AGs) to obtain the best fin model for the studied profiles. Finally, they concluded that this technique was well suited to solving most problems studied in the literature.Moleofane and Moistsheki (2014) carried out a study on heat transfer in several fins profiles, among which the rectangular, radial and spherical profiles stand out. They considered the thermal conductivity and the convective coefficient to be temperature dependent, and found that the heat dissipation in the spherical profile fin is much slower than in the other studied profiles. They also compared efficiency and effectiveness between fins, concluding that the spherical fin performed the worst.

Balachandar et al. (2015), when considering the assembly of a set of fins on a heat exchanger, studied the optimization of the relative positioning among them, using the genetic algorithm (GA), applied in neural networks. They compared several profiles and found that one of hollow cylindrical pin type had higher rate of heat dissipation and significant reduction in weight than other profiles. Yang et al. (2016) carried out a study on rectangular fins, varying the thickness and width of the base parameters, comparing their thermal performance with that of uniformly thick fins.

The present work deals with the use of specific types of fins mounted on electrical equipments of wide industrial use, which present a great need for cooling. The industrial equipment chosen for analysis are: three-phase transformer, three-phase induction motor and frequency inverter. The study aims to justify on an approximate base, the use of specific finsby the manufacturers(Ferreira, 2018).This theoretical approach proposes a methodology to supply the lack of technological and operational information usually denied by manufacturers. This methodology starts from the possibility of measuring all actual physical dimensions of the fins mounted on any equipment. After that, making use of theoretical concepts established in the pertinent literature, a fin profile with similar conditions of applicability must be chosen in order to compare thermal performances between them, both submitted to identical test conditions.

\section{MATHEMATICAL MODELING}

With regard to the equipments under study, the transformer and frequency inverter fins have a longitudinal rectangular profile, while the profile of the fin of the induction motor has a trapezoidal longitudinal shape.Due to the need of evaluating the thermal performance of the original fins, an alternative fin profile should be proposed to make such comparison.Thus, a solid longitudinal cylindrical pin profile was chosen, since it has a similar application involving gases (air), in addition to gathering simplicity of manufacture and uniform thickness.However, it should be noted that the comparison between trapezoidal and cylindrical profiles requires an approximation for the former.For this purpose, an approximation of the motor fins from the trapezoid to the rectangular shape was assumed, which will be exposed later.Nevertheless, such an approach is evaluated to infer its influence, when comparing thermal performances between the original and alternative profiles.

The basic conditions considered in previous works by Murray (1938) and Gardner (1945) were also adopted in the present study, which are given by:

1. The heat conduction in the fin is steady and one-dimensional.

2. The fin material is homogeneous and isotropic.

3. The temperature of the base of the fin is uniform.

4. There is no internal heat generation in the fin.

5. The convection environment temperature is uniform.

6. Heat flow through the fin tip is negligible.

7. The thermal conductivity of the fin is constant.

8. Heat dissipated from the fin surface at any position is directly proportional to the temperature difference between the surface at that position and the environment.

9. There is perfect thermal contact between the base of the fin and the primary surface.

10. The heat transfer coefficient between the fin and the environment is constant and uniform over the entire surface of the fin.

The schematic of the fins with a rectangular and cylindrical profile, which will be considered in the present study, is shown in Fig. 1. It can be noted that the longitudinal axis of the fins was associated with 
the coordinated direction, indicated by the $\mathrm{x}$-axis. The rectangular fin(Fig. 1a) is of length $L$, thickness w and width b, while the cylindrical fin(Fig. 1b) is of length $\mathrm{L}$ and diameter D.On the other hand, the thermal conductivity is denoted by $\mathrm{k}$, the temperature of the base of the fin by $\mathrm{T}_{\mathrm{b}}$, the environment temperatureby $\mathrm{T}_{\infty}$ andall surfaces of thefinsare exposed to a convective heat transfer coefficient $h$.

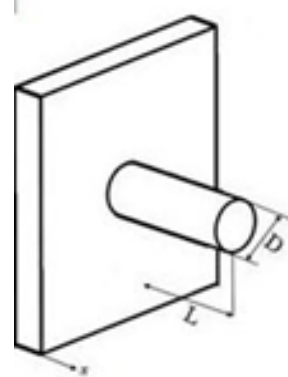

(a)

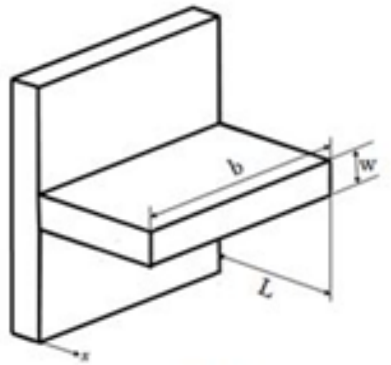

(b)
Figure 1. Longitudinal fins of constant cross section(Nnanna et al., 2003and Bergman, 2011).

The rate of heat dissipation of a fin, q, depends on the longitudinal distribution of temperature. Therefore, the general fin equation (Nnanna et al., 2003) and (Bergman, 2011), after being simplified by the considerations previously described in the present work, is expressed by

$$
\frac{\mathrm{d}^{2} \mathrm{~T}(\mathrm{x})}{\mathrm{dx^{2 }}}-\frac{\mathrm{kA}_{\mathrm{ST}}}{\mathrm{hP}}\left(\mathrm{T}(\mathrm{x})-\mathrm{T}_{\infty}\right)=0,
$$

where $\mathrm{T}(\mathrm{x})$ is the local fin temperature, ${ }^{\circ} \mathrm{C}, \mathrm{A}_{\mathrm{ST}}$ is the cross-sectional area, $\mathrm{m}^{2}$, and $\mathrm{P}$ is the transverse perimeter of the fin, $\mathrm{m}$. The boundary conditions applicable to the present study are given by:

$$
\begin{gathered}
T(0)=T_{b} \\
\left.\frac{\partial T}{\partial x}\right)_{x=L}=0
\end{gathered}
$$

and the heat dissipation rate denoted by q, W, is calculated using the following expression:

$$
q=\int_{0}^{L} h P\left(T(x)-T_{\infty}\right) d x
$$

\section{METHODOLOGY}

The scope of this work is to investigate the use of specific fin profiles in three industrial electrical devices namely: three-phase-transformer, three-phase induction motor and frequency inverter. An approximate approach is adopted due to the lack of technical and operational information that is normally denied by manufacturers. To overcome this difficulty, a methodology is proposed in the present study to evaluate the use of the original fins, as described below.

As an alternative in the absence of physical data related to the original fins, such data were accessed in a company that allowed us to get them. So, the volumes of each type of finwere obtainedfrom the measurementsofall dimensions.On the other hand,in order to compensate for the absence of operational data, a criterion was followed to indicate which profile wouldbe moresuitable.Therefore, thecriteriondefined by Aziz andKraus(1995) was adopted, which calculates the maximum heat dissipation rate produced by the fin, based on the knowledge of its original dimensions and volume, through optimization of its dimensions. To meet this criterion, the volumes of each rectangular profile fin were utilized as the volume to be adopted for each fin of cylindrical profile. Table 1 shows the physical dimensions of the original fins mounted onthe selected equipments and these dimensions led to fin volumes of $3.836 \times 10^{-4} \mathrm{~m}^{3}$ for the transformer, 3.126 $\mathrm{x} 10^{-5} \mathrm{~m}^{3}$ for the inverter and $1.551 \times 10^{-5} \mathrm{~m}^{3}$ for the motor.

Table 1. Original physical dimensions of the fins.

\begin{tabular}{cc}
\hline Equipments & Dimensions (m) \\
\hline & $\mathrm{L}=0.0100$ \\
$\mathrm{w}=0.5480$ \\
$\mathrm{~b}=0.0700$
\end{tabular}

In relation to the trapezoidal profile fin of the motor, it is verified that the angle of inclination of the longitudinal dimension with the direction of the $\mathrm{x}$ coordinate is $1.9^{\circ}$. Therefore, in this case, it was assumed to be possible to approximate this trapezoidal profile to a rectangular one, whose expression for the proposed thickness $\mathrm{w}, \mathrm{m}$, is given by

$$
\mathrm{w}=\frac{\mathrm{w}_{1}+\mathrm{w}_{2}}{2}
$$

and for the measured length $\mathrm{L}, \mathrm{m}$, as shown in Tab. 1, its projection on the direction of the $\mathrm{x}$ axis is given byL $\cos (1.9) \cong$ L. Therefore, the new measures after applying such approximation from trapezoidal to 
rectangular shape, whose original volume did not change, become $\mathrm{L}=0.0150 \mathrm{~m}, \mathrm{w}=0.0055 \mathrm{~m}$ and $\mathrm{b}=$ $0.1880 \mathrm{~m}$.

In the present study, it was established that the numerical value of the fin base area, for both cylindrical and rectangular profile, per equipment, is identical. Thus, under equal operating conditions to be imposed on the two types of fin, the heat transfer rate that leaves out the hot wall to the environment through this area free of finwill be the same for both fins. Therefore,itbecomes possibleto calculate and compare theeffectiveness of the two profiles.

Further, the longitudinal length of each cylindrical profile (L) wasdimensioned to be of equal value as thatof thecorrespondent rectangular profile.Besides that, thediameterswere determinedthrough the respectivearea of fin base and are denoted by dimension $\mathrm{D}$. These two dimensions are shown in Tab. 2 for each device.

With the datashown in Tab. 1 and Tab.2 and considering the fins as being of the same material, the optimization process mentioned above was applied. This process uses different expressions to determine the ideal dimensions for each profile. Thus, in the case of a rectangular profile fin, the optimized thickness $\mathrm{w}$ and length $\mathrm{L}$ are represented by:

$$
\begin{aligned}
& \mathrm{w}_{\mathrm{opt}}=0.9977\left(\frac{\mathrm{A}_{\mathrm{P}}^{2} \mathrm{~h}}{\mathrm{k}}\right)^{1 / 3} \\
& \mathrm{~L}_{\text {opt }}=1.0023\left(\frac{\mathrm{A}_{\mathrm{P}} \mathrm{k}}{\mathrm{h}}\right)^{1 / 3}
\end{aligned}
$$

where $A_{P}$ is the area of the longitudinal profile, $\mathrm{m}^{2}$, and in this case, $A_{P}=w L$. With the values of $w_{\text {opt }}$ and $\mathrm{L}_{\mathrm{opt}}$, it is possible to obtain the value of $\mathrm{b}_{\mathrm{opt}}$, once the actual volume is known. As for the cylindrical longitudinal profile, the optimal dimensions of the diameter and length are calculated by the following expressions:

$$
\begin{aligned}
& \mathrm{D}_{\text {opt }}=1.5031\left(\frac{\mathrm{h} \mathrm{V}^{2}}{\mathrm{k}}\right)^{1 / 5} \\
& \mathrm{~L}_{\mathrm{opt}}=0.5636\left(\frac{\mathrm{V} \mathrm{k}^{2}}{\mathrm{~h}^{2}}\right)^{1 / 5}
\end{aligned}
$$

where $V$ is the volume of the fin, $\mathrm{m}^{3},\left(\mathrm{~V}=\left(\pi \mathrm{D}^{2} /\right.\right.$ 4)L). Thus, the optimized dimensions for the transformer, motor and inverter fins are shown in Tab.3, Tab.4 and Tab.5, respectively.

Using the data contained in Tabs. 3-5, the calculations of the maximum heat dissipation rates for each type of fin, q, areperformed through Eq.
(4), as well as the calculations of their effectiveness, $\varepsilon$ ,are obtained through expressed by

$$
\varepsilon=\frac{\mathrm{q}_{\max }}{\left[\mathrm{hA}_{\mathrm{st}}\left(\mathrm{T}_{\mathrm{b}}-\mathrm{T}_{\infty}\right)\right]}
$$

\section{RESULTS AND DISCUSSION}

The application of the original fins used in thethree industrial equipments treated here is studied bycomparingthe effectiveness values of these fins with the effectiveness of the fins of cylindrical profile,having already been considered the approximation from trapezoidal to a rectangular profile in case of the motor. Allcomparisons were made underidenticaloperational conditions, whichinvolve theenvironment temperature, the convective heat transfer coefficient and the temperatureof the fin base.

Table 2. Physical dimensions of cylindrical profile fin.

\begin{tabular}{cc}
\hline Equipments & Dimensions (m) \\
\hline \multirow{2}{*}{ Transformer } & $\mathrm{L}=0.0100$ \\
& $\mathrm{D}=0.2210$ \\
\hline \multirow{2}{*}{ Inverter } & $\mathrm{L}=0.0610$ \\
& $\mathrm{D}=0.0260$ \\
\hline \multirow{2}{*}{ Motor } & $\mathrm{L}=0.0150$ \\
& $\mathrm{D}=0.0360$ \\
\hline
\end{tabular}

Table 3. Optimized fin dimensions: Transformer.

\begin{tabular}{cc}
\hline Geometry & Dimensions (m) \\
\hline Rectangular longitudinal & $\mathrm{L}_{\mathrm{opt}}=0.3200$ \\
profile & $\mathrm{W}_{\mathrm{opt}}=0.0171$ \\
& $\mathrm{~b}_{\mathrm{opt}}=0.0700$ \\
\hline Cylindrical longitudinal & $\mathrm{L}_{\mathrm{opt}}=0.2383$ \\
profile & $\mathrm{D}_{\mathrm{opt}}=0.0453$ \\
\hline
\end{tabular}

Table 4. Optimized fin dimensions:Motor.

\begin{tabular}{cc}
\hline Geometry & Dimensions (m) \\
\hline Rectangular longitudinal & $\mathrm{L}_{\text {opt }}=0.0790$ \\
profile & $\mathrm{w}_{\mathrm{opt}}=0.0010$ \\
& $\mathrm{~b}_{\mathrm{opt}}=0.1880$ \\
\hline Cylindrical longitudinal & $\mathrm{L}_{\text {opt }}=0.1255$ \\
profile & $\mathrm{D}_{\text {opt }}=0.0125$ \\
\hline
\end{tabular}

Table 5. Optimized fin dimensions:Inverter.

\begin{tabular}{cc}
\hline Geometry & Dimensions (m) \\
\hline Rectangular longitudinal & $\mathrm{L}_{\text {opt }}=0.0970$ \\
profile & $\mathrm{w}_{\mathrm{opt}}=0.0016$ \\
& $\mathrm{~b}_{\mathrm{opt}}=0.2050$ \\
\hline Cylindrical longitudinal & $\mathrm{L}_{\text {opt }}=0.1444$ \\
profile & $\mathrm{D}_{\text {opt }}=0.0166$ \\
\hline
\end{tabular}


To calculate the heat dissipation rate performedby the fin, first it is necessary to solve Eq. (1) toobtain the longitudinal temperature distribution along the fin. This equation was solved numerically through the Finite Difference Method and to solve the discretization equation it was applied the iterative method of Gauss Seidel.

The validation of the computational code was carried out with the resolution of a test problem involving a longitudinal rectangular profile fin, which presents an exact solution for Eq. (1).The parametersconsideredin the test problem are: $\mathrm{L}=0.5$ $\mathrm{m} ; \mathrm{b}=0.05 \mathrm{~m} ; \mathrm{w}=0.006 \mathrm{~m} ; \mathrm{T}_{\infty}=25^{\circ} \mathrm{C} ; \mathrm{k}=398 \mathrm{~W} /(\mathrm{m}$ $\left.{ }^{\circ} \mathrm{C}\right) ; \mathrm{h}=100 \mathrm{~W} /\left(\mathrm{m}^{2 \mathrm{o}} \mathrm{C}\right)$.

The boundaryconditions used and theexactsolution of Eq. (1) for this test problem are given respectively by:

For $\begin{cases}\mathrm{x}=0, & \mathrm{~T}(0)=100{ }^{\circ} \mathrm{C} \\ \mathrm{x}=\mathrm{L}, & -\left.\mathrm{k} \frac{\partial \mathrm{T}}{\partial \mathrm{x}}\right|_{\mathrm{x}=\mathrm{L}}=\mathrm{h}\left[\mathrm{T}(\mathrm{L})-\mathrm{T}_{\infty}\right]\end{cases}$

$\mathrm{T}(\mathrm{x})=\mathrm{T}_{\infty}+\left(\mathrm{T}_{\mathrm{b}}-\mathrm{T}_{\infty}\right)$

$\left(\frac{\cosh \left[m_{0}(L-x)\right]+\left(h /\left(m_{0} k\right)\right) \operatorname{senh}\left[m_{0}(L-x)\right]}{\cosh \left(m_{o} L\right)+\left(h /\left(m_{0} k\right)\right) \operatorname{senh}\left(m_{0} L\right)}\right)$

wherem $_{0}=\sqrt{\mathrm{hP} / \mathrm{kA}_{\mathrm{ST}}}$.

The computational mesh was defined through a mesh test, where simulations with 20, 60, 100 and 140 nodal points were considered. The criterion for choosing the mesh was to assess the largest percentage gap between numerical value $\left(\mathrm{T}_{\mathrm{N}}\right)$ and exact value $\left(\mathrm{T}_{\mathrm{E}}\right)$ that occurred among all points of the mesh, whose value should be less than $0.15 \%$. The test revealed that the mesh with 100 nodal points already met the imposed condition, with no need to use the mesh with 140 nodal points, which would imply additional computational cost without need.

Finally, the converged solution to be adopted as the final numerical solution is that for which the module of the maximum difference found between the value of the current iteration $\left(\mathrm{T}_{\mathrm{i}}^{\mathrm{n}+1}\right)$ and the value of the previous iteration $\left(\mathrm{T}_{\mathrm{i}}^{\mathrm{n}}\right)$ at a nodal point, following this check procedure for all points, should be less than $1 \times 10^{-6}$, i.e., $\left|\mathrm{T}_{\mathrm{i}}^{\mathrm{n}+1}-\mathrm{T}_{\mathrm{i}}^{\mathrm{n}}\right|_{\max } \leq 1 \times 10^{-6}$, where $\mathrm{n}$ represents the interaction number.Therefore, Fig. 2 shows the result of the mesh test and Tab. 6 describes some differences between numerical and analytical or exact values in some points, in order to better illustrate the differences, since the two curves are very nearby along its extensions, what validates the computational code.

Returning to the object of study, the common operating conditions for calculating the maximum heat dissipation rates for the rectangular and cylindrical profiles through Eq. (4) and Tabs. 3-5, as well as the effectiveness of the fins through Eq. (10), are shown in Tab. 7. It should be remembered that in all calculations, the boundary condition at the tip of the fins is that of no exchange of heat.Finally, all maximum rates of heat dissipation and effectiveness, per equipment, are shown in Tab. 8.

Analyzing Tab. 8, it appears that the different rates found between the two profiles can be attributed to the differences between their surface areas, after the optimization procedure performed by Eqs. (6)-(9), based on the data presented in Tabs. 12.Such optimization processes established optimal values of length and thicknessfor the rectangular profile, and of length anddiameter for thecylindricalprofile. Thus,keeping the volumeconstant, the width ofthe rectangularprofile finbasealso changes, creating a new cross-sectional area of the fin base, i.e., $A_{\mathrm{st}}=\mathrm{w}_{\mathrm{opt}} \mathrm{b}_{\mathrm{opt}}$. It leadstoa newsurfacearea of heat exchange byconvection. With respect to the fins of cylindrical profile,designedwith the same volume as those of theoriginal fins of rectangular profile, it is noticed thatthe optimal values of length and diameter also led to a change in the surface areas. Therefore, the largestsurface areas result in the highest rates of heat dissipation.

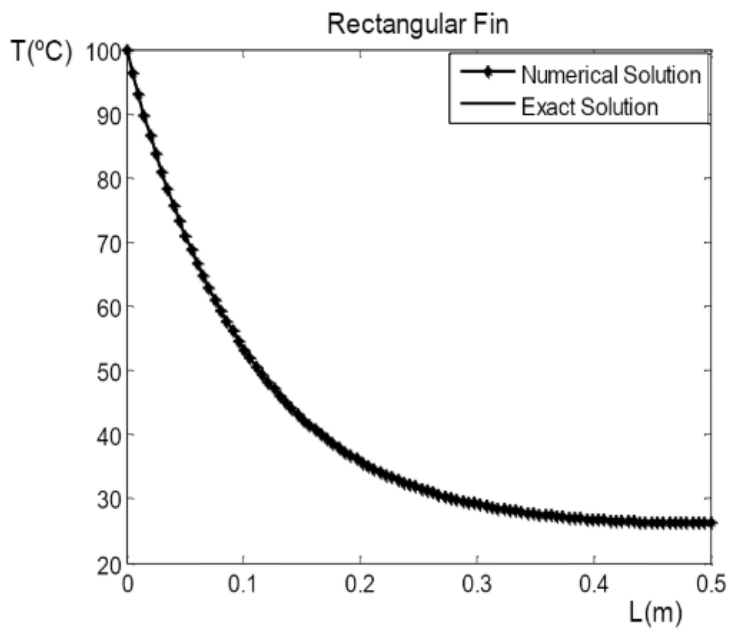

Figure 2. Temperature distribution for 100 nodal Points.

Table 6. Comparison between solutions: Meshtest.

\begin{tabular}{cccc}
\hline $\mathrm{x}(\mathrm{m})$ & $\mathrm{T}_{\mathrm{N}}\left({ }^{\circ} \mathrm{C}\right)$ & $\mathrm{T}_{\mathrm{E}}\left({ }^{\circ} \mathrm{C}\right)$ & $\left(\left|\mathrm{T}_{\mathrm{N}}-\mathrm{T}_{\mathrm{E}}\right| / \mathrm{T}_{\mathrm{E}}\right) 100$ \\
\hline 0.2980 & 29.2732 & 29.2641 & 0.0308 \\
\hline 0.3030 & 29.0778 & 29.0683 & 0.0323 \\
\hline$\ddot{.}$ & $\ddot{.}$ & $\ddot{.}$ & $\ddot{.}$ \\
\hline 0.3081 & 28.8921 & 28.8823 & 0.0339 \\
\hline 0.3131 & 28.7158 & 28.7055 & 0.0359 \\
\hline 0.3182 & 28.5483 & 28.5376 & 0.0375 \\
\hline 0.3232 & 28.3894 & 28.3782 & 0.0395 \\
\hline
\end{tabular}

Table 7. Operating conditions of the fins.

\begin{tabular}{cc}
\hline Thermal Parameters & $\begin{array}{c}\text { Rectangular/Cylindrical } \\
\text { Profiles }\end{array}$ \\
\hline $\mathrm{h}\left(\mathrm{W} / \mathrm{m}^{2 \circ} \mathrm{C}\right)$ & 40
\end{tabular}




\begin{tabular}{cc}
\hline $\mathrm{k}\left(\mathrm{W} / \mathrm{m}^{\circ} \mathrm{C}\right)$ & 237.5 \\
\hline $\mathrm{T}_{\mathrm{b}}\left({ }^{\circ} \mathrm{C}\right)$ & 65 \\
\hline $\mathrm{T}_{\infty}\left({ }^{\circ} \mathrm{C}\right)$ & 25 \\
\hline
\end{tabular}

Table 8. Final results of the comparison between rectangular and cylindrical profiles.

\begin{tabular}{cccc}
\hline Equipment & Profile & $\mathrm{q}_{\max }(\mathrm{W})$ & $\varepsilon$ \\
\hline \multirow{2}{*}{ Transformer } & rectangular & 51.79 & 27.01 \\
& cylindrical & 42.80 & 16.62 \\
\hline \multirow{2}{*}{ Motor } & rectangular & 29.90 & 99.40 \\
& cylindrical & 6.25 & 31.57 \\
\hline \multirow{2}{*}{ Inverter } & rectangular & 40.07 & 76.35 \\
& cylindrical & 9.51 & 27.44 \\
\hline
\end{tabular}

The results presented in Tab. 8 indicate for thethree-phase transformer that the maximum heat dissipation rate of the rectangular profile fin is $21 \%$ higherthan the maximum ratedissipated by thecylindrical fin. With regard to the motor and the inverter, these superiorities are $378.4 \%$ and $321.34 \%$, respectively. These results are expected, as previously mentioned due to differences in surface areas. For the transformer, the surface area of the rectangular profile is $64.37 \%$ greater than that of the cylindrical profile, and for the motor and inverter, these superiorities are 505.92\% and $432.24 \%$, respectively. Thus, these differences are reflected in the effectiveness parameter, whose values corresponding to the rectangular longitudinal profiles are vastly superior to those of the cylindrical longitudinal profiles. It should be noted that the geometric approximation from trapezoidal to rectangular profile, in the case of the motor, had little influence on the comparison between the effectiveness found for the two profiles, having seen the great difference found.

\section{CONCLUSIONS}

A methodology was outlined in the present work in order to verify the use of specific fins in industrial equipments, dealing with the absence of technical and operational data concerned with the fins.

The application of this methodology begins with measurements of the original fin physical dimensions, due to the lack of technical information on the part of the equipment manufacturers. Since the operating conditions of the fins are not known, the actual dimensions are employed in an optimization process, which is based on the knowledge of the original fin volume. Thus, with the optimized dimensions, the maximum heat dissipation rates can be calculated. However, one or more fin profiles that are part of the same application, must be chosen for comparison with the original profile. On the other hand, the dimensions of these alternative profiles must be designed based on the volume of the original fin and subsequently be also submitted to the same optimization process.

In the study treated here, the target equipments were: three-phase transformer, three-phase motor and frequency inverter. The fins mounted on the transformer and inverter have a longitudinal rectangular profile, while the fins on the motor have a trapezoidal longitudinal profile.As an option for comparison with the original fins, longitudinal fins with solid cylindrical pin type of similar application were chosen.It is noteworthy, however, that for the motor fin to meet the comparison with this cylindrical profile, an approximation from the trapezoidal to a rectangular profile was performed.The comparison between the two profiles took place under identical operating conditions.

The analysis showed that the fins of rectangular profile presented thermal performance much higher than those of cylindrical profile. This superiority occurs due to the surface areas of the original fins be much largerthan those of the fins of cylindricalprofile, after optimization of the dimensions.

It is also noted that thesuperiority of themaximum heat dissipation rates of the motor fins, which were approximated from trapezoidal profile to rectangular profile, are also significantly higher than the rates of the cylindrical profile. This fact indicates that such geometric approximation was of little relevance. Therefore, the methodology developed in the present study showed results that can be considered as positive to justify the use of the fins found in the three equipments discussed here, in view of their high effectiveness values for the fins of rectangular profile in contrast to those presented for the fins of cylindrical profile.

\section{REFERENCES}

Aziz, A., 1992, Optimum Dimensions of Extended Surfaces Operating in a Convective Environment, Applied Mechanics Reviews, Vol. 45, No. 5, pp. 155-173.

Aziz, A., and Kraus, A. D., 1995, Transient Heat Transfer in Extended Surfaces, Applied Mechanics Reviews,Vol. 48, No. 7, pp. 317-350.

Aziz, A., and Fang, T., 2010, Alternative Solutions for Longitudinal Fins of Rectangular, Trapezoidal, and Concave Parabolic Profiles, Energy Conversion and Management,Vol. 51, No. 11, pp. 2188-2194.

Balachandar, C., Arunkumar, S., and Venkatesan, M., 2015, Computational Heat Transfer Analysis and Combined ANN-GA Optimization of Hollow Cylindrical Pin Fin on a Vertical Base Plate, Sadhana, Vol. 40, No. 6, pp. 1845-1863.

Bergman, T. L., Incropera, F. P., Dewitt, D. P., and Lavine, A. S., 2011, Fundamentals of Heat and Mass Transfer, John Wiley \& Sons. 
Eu O., Kang, O. L., K., Seetharamu, K. N, Azid, I. A, Quadir, G. A, Zainal, Z. A, and Joo Goh, T., 2005, Optimization of Fins Used in Electronic Packaging, International Journal of Microelectronics, Vol. 22, No. 1, pp. 10-15.

Ferreira, A. L. G., 2018, Estudo Numérico sobre Arrefecimento por Aletas em Dispositivos Elétricos Industriais, Master Thesis, PPG-Modelagem Computacional em Ciência e Tecnologia, EEIMVRUFF, Volta Redonda, RJ, (in Portuguese)

Gadner, K. A., 1945, Efficiency of Extended Surface, Trans. ASME, Vol. 67, pp. 621-627.

Ganorkar, A. B., and Kriplani, V. M., 2011, Review of Heat Transfer Enhancement in Different Types of Extended Surfaces, International Journal of Engineering Science and Technology, Vol. 3, No. 4, pp.3304-3315.

Kraus, A. D.,1988, Sixtyfive Years of Extended Surface Technology (1922-1987), Applied Mechanics Reviews, Vol. 41, No. 9, pp. 321-364.

Marchetta, J. G., Perry, E. H., Schultz, M. D., Grizzard, M. R., and Butler, B. A.,2008, Using Extended Surfaces to Reduce the Thermal Signatures of Military Assets, Proceedings of SPIE Defense and Security Symposium, Vol. 6941, pp. 69411D1$694911 \mathrm{D} 12$.

Mokheimer, E. M., 2003, Heat Transfer from Extended Surfaces Subject to Variable Heat Transfer Coefficient, Heat and Mass Transfer, Vol. 39, No. 2, pp. 131-138.

Moleofane, K.J., and Moitsheki, R. J., 2014, Comparison of Exact Solutions for Heat Transfer in Extended Surfaces of Different Geometries, Abstract and Applied Analysis, Vol. 2014, Special Issue.

Murray, W. M., 1938, Heat Flow Through an Annular Disk or Fin of Uniform Thickness, Trans ASME J Appl. Mech, Vol. 60, A78.

Nagarani, N., Mayilsamy, K., Murugesan, A. and Kumar, G. S.,2014, Review of Utilization of Extended Surfaces in Heat Transfer Problems, Renewable and Sustainable Energy Reviews, Vol. 29, pp. 604-613.

Nnanna, A. G. A., Haji-Sheikh, A., and Agonafer, D.,2003, Effect of Variable Heat Transfer Coefficient, Fin Geometry, and Curvature on the ThermalPerformance of Extended Surfaces, Journal of Electronic Packaging,Vol. 125, No. 3, pp. 456460.

Yang, A., Chen, L., Xie, Z., Feng, H., and Sun, F., 2016, Thermal Performance Analysis of NonUniform Height Rectangular Fin Based on Constructal Theory and EntransyTheory, Science China Technological Sciences, Vol. 59, No. 12, pp. 1882-1891. 